\title{
The Role of Creb in Adipogenesis through Mammalian Target of Rapamycin of Complex 1 (mTORC1) Pathyway
}

\author{
Triawanti, M. Rasjad Indra, Askandar Tjokroprawiro, Hidayat Sujuti, and Eko Suhartono
}

\begin{abstract}
One of the tissues taking the biggest part in the pathogenesis of obesity is adipose tissue mainly formed by white fat cells. Recently, the processes adipogenesis become a treatment target for obesity. One of the pathway that allegedly participated in the process of adipogenesis is activated via CREB. The upstream pathway is by means of protein of mammalian targets of rapamycin (mTOR). This study was aimed to determine the role of CREB in adipogenesis through the activation of p70S6K1 by mTORC1.

This was an experimental study. Subjects were primary cultured preadipocytes taken from visceral fat of white rats (Rattus norvegicus). Cell cultures were classified into 4 groups: (K) Control of adipogenesis: without rapamycin and RNAi CREB, (A): was given rapamycin $10 \mathrm{nM},(B)$ : was given RNAi CREB $100 \mathrm{nM}$, (C): was given rapamycin $10 \mathrm{nM}$ and RNAi CREB 100 nM. p70S6K1, CREB activation, and expression of C/EBP $\delta$ measured on day 2, 4, and 6, and the morphology of adipocytes on day 6. Data were analyzed with Anova test, LSD test, and Pearson correlation test with $95 \%$ confidence level.

The data showed that rapamycin activated p70S6K1 and caused lower CREB compared with control group during adipogenesis. These results indicated that adipogenesis was blocked, which resulted from the inhibition of p70S6K1 and CREB activation by rapamycin and RNAi CREB. The inhibition was stronger in rapamycin + RNAi CREB group. Statistically, there was significant correlation between p70S6K1 and CREB; and between CREB and C/EBP $\delta$.
\end{abstract}

It was concluded that the role of CREB in adipogenesis was mediated by the activation of p706K1 by mTORC1.

Index Terms-Obesity, adipogenesis, mTORC1, p70S6K1, CREB, C/EBPס.

\section{INTRODUCTION}

Obesity is defined as a disorder resulted from accumulated body fat, which may have detrimental effects on health. Obesity is the main factor of several diseases, including coronary heart disease, hypertension, non-insulin-dependent diabetes mellitus (NIDDM), pulmonary disfunction, osteoarthritis, certain cancers [1], [2] and serious mental disorders [2]. Almost 1.6 billion adults worldwide had overweight condition, and at least 400 million of them had obesity. In 2015, it is estimated that 2.3 billion adults will

Manuscript received November 23, 2013; revised January 14, 2014.

Triawanti, Hidayat Sujuti, and Eko Suhartono are with the Medical Chemistry/ Biochemistry Department Faculty of Medicine Lambung Mangkurat University, Banjarmasin, Indonesia (e-mail: tria_fkunlam@yahoo.co.id, hidayatsujuti@yahoo.com, ekoantioksidan@ yahoo.com)

M. Rasjad Indra is with the Department of Physiology, Faculty of Medicine, Brawijaya University, Malang, Indonesia (e-mail: rasjadindra@yahoo.com)

Askandar Tjokroprawiro is with the Center of Diabetes and Nutrition RSUD Dr Soetomo, Faculty of Medicine, Airlangga University, Surabaya, Indonesia (e-mail: rachman_syah2002@yahoo.com). have overweight, and 700 million of them will have obesity. Meanwhile, at least 20 million under-five-years-old children had obesity globally in 2005 [3].

One of the tissues with the biggest role in the pathogenesis of obesity is adipose tissue. In obesity, white fat tissue accumulation is occurred, results from the increase in the size of fat cells (hypertrophy) and the increase in new mature cells from precursors which previously are not differentiated (hyperplasia). The process of differentiation and maturation of adipocytes has become one of the target for treatment of obesity [4]. One of the pathways assumed to be activated in adipogenesis is via mammalian Target of Rapamycin (mTOR) protein. In mTORC1 pathway, p70S6K1 protein is phosphorylated, and in turn it will activate various downstream proteins. The increase in adiposity is minimal by adipogenesis acceleration, with the increase in the expression of $\mathrm{C} / \mathrm{EBP} \delta, \mathrm{C} / \mathrm{EBP} \alpha$, and PPAR $\gamma$.

Other protein also suspected to have the role in $\mathrm{mTORC} 1$ pathway in adipogenesis process is cAMP respon element binding protein (CREB). In adipogenesis process, CREB protein has initial function, and furthermore it will regulate the expression of C/EBP $\alpha$ dan PPAR $\gamma$ [4]. In preadipocyte, expression of $\mathrm{C} / \mathrm{EBP} \beta$ dan $\mathrm{C} / \mathrm{EBP} \delta$ is upregulated by the activation of prostacyclin receptor which induces the binding of CREB and/or ATF-1 (activation transcription factor 1) to C/EBP promoter [5]. De Groot et al. in El-Charr et al. [6] reported that CREB was regulated by p70S6K. However, there has been no studies which evaluate the mTORC1 $\rightarrow$ p70S6K1 $\rightarrow$ CREB $\rightarrow$ CEBP $\delta$ pathway extensively. A study to develop a comprehensive concept or model on the role of CREB in adipogenesis process through the activation of p70S6K1 by mTORC1 is needed.

If the basic concept of adipogenesis is proven and it is developed into a concept of comprehensive pathway, it will be easier to look for points of therapeutic target for obesity in the upstream, namely, by preventing preadipocyte to become mature adipocyte, resulting in the decrease in total adipocytes.

\section{MATERIAL AND METHODS}

\section{A. Material}

Materials used in this study were collagenase type I (Sigma), HEPES solution, NaHCO3, biotin, D-pantothenate and $10 \%$ FBS, nylon mesh, adipogenic medium (DMEM/F12 added with $100 \mathrm{U} / \mathrm{mL}$ penicillin and $100 \mathrm{U} / \mathrm{mL}$ streptomycin, $66 \mathrm{nM}$ insulin, $100 \mathrm{nM}$ dexamethasone, $0.5 \mathrm{mM}$ IBMX), 95\% ethanol, Dulbecco phosphate buffer saline (dPBS) as washing solution, deionized water as solvent, Rapamycin, L-glutamate. To block the CREB, mouse RNAi CREB (Santa Cruz Biotech. No Cat. sc-35111), siRNA dilution (Santa 
Cruz Biotech. No Cat. sc 29527), siRNA transfection medium (Santa Cruz Biotech. No Cat. sc 36868), siRNA transfection reagent (Santa Cruz Biotech. No Cat. sc 29528), Oil Red O, $10 \%$ formalin, Meyer hematoxylin, $85 \%$ propylene glycol, $100 \%$ propylene glycol, gelatin, aquadest, $\mathrm{DAB}$, streptavidin horse radish peroxidase (SA-HRP), and entellan were used. Primary antibodies used for immunocytochemistry examination were polyclonal rat anti p70S6K1 Ser424/Thr421 (Santa Cruz Biotech. No. Cat. sc-7984-R), rat anti CEBP/ $\delta$ (Santa Cruz Biotech. No cat. sc-151) and rat-anti phospho-spesific CREB (Ser133) (Santa Cruz Biotech. No. Cat. sc-101663). For immunocytochemistry staining, ImmunoCruz mouse LSAB staining system (Santa Cruz Biotech. No Cat. sc-2050) was used.

\section{B. Cell Culture and Treatment}

This study used the primary cultures of preadipocytes, taken from visceral adipose tissue of male white rats (Rattus norvegicus 4-6 weeks old). Preadipocytes were isolated from visceral adipose tissue of rats, and then cultured, and their adipogenesis process was induced. It was a laboratory experimental study, using the primary culture of preadipocytes, with posttest-only with control group design. Cultures of preadipocytes were classified into treatment groups as follows:

1) Adipogenesis control group: culture of adipocytes, which differentiation was induced, without the addition of rapamycin and RNAi CREB.

2) Treatment group A: culture of adipocytes, which differentiation was induced, with the addition of rapamycin in the dose of $10 \mathrm{nM}$.

3) Treatment group B: culture of adipocytes, which differentiation was induced, with the addition of RNAi CREB inhibitor $100 \mathrm{nM}$, without rapamycin.

4) Treatment group C: culture of adipocytes, which differentiation was induced, with the addition of RNAi CREB inhibitor $100 \mathrm{nM}$ and rapamycin $10 \mathrm{nM}$. Each treatment was replicated 6 times.

\section{Cell Isolation and Culture}

Preadipocytes were isolated surgically from visceral fat tissue of white rats (Rattus norvegicus) from Wistar strain, in the age of 4-6 weeks. Rats were given anesthetic agent ketamine before surgery. Abdominal cavity was exposed and fat tissue in retroperitoneal space and epidydimis was obtained with aseptic technique. Fat tissue obtained was soaked in transport solution. Next process was to be conducted in culture room. Fat tissue was separated from fibrous tissue and blood vessels, and then it was washed and chopped. The tissue suspension was incubated with $0.2 \%$ $\mathrm{mg} / \mathrm{mL}$ Collagenase type I (Sigma) for 45-60 minutes in the temperature of $37^{\circ} \mathrm{C}$ with shaking. Incubation was stopped, and culture medium (DMEM/F12 (1:1) added with 15 $\mathrm{mmol} / \mathrm{L} \mathrm{HEPES}, 14 \mathrm{mmol} / \mathrm{L} \mathrm{NaHCO}_{3}$, and 10\% FBS) which already filtrated with nylon mesh $(250 \mu \mathrm{m})$ was added. Cell suspension was sentrifuged with the rotation speed of 1500 rpm for 7 minutes, and the fat layer (mature adipocytes and fat droplets) in supernatant was discarded. Pellet which contained fibroblast-like preadipocytes was resuspended with culture medium, and then the cells were centrifugated with rotation speed of $1500 \mathrm{rpm}$ for 7 minutes. Pellet was resuspended again with culture medium. Afterwards, cells were grown on 24-well plate already covered with cover glass and lined with gelatin, and culture medium containing $10 \%$ FBS was added. Cells were also grown in flask containing culture medium $+10 \%$ FBS [7].

\section{Differentiation Induction of Cells and the Administration of Rapamycin and RNAi CREB}

After $70-80 \%$ confluence of preadipocytes was reached, cells were grown in adipogenic medium (DMEM/F12 added with $100 \mathrm{U} / \mathrm{mL}$ penicillin and $100 \mathrm{U} / \mathrm{mL}$ streptomycin, 66 $\mathrm{nM}$ insulin, $100 \mathrm{nM}$ dexamethasone, $0.5 \mathrm{mM}$ isobuthylmethylxanthine [IBMX]). Rapamycin was dissolved in DMSO solvent. Group A was given rapamycin $10 \mathrm{nM}$, group B was given RNAi CREB $100 \mathrm{nM}$, and group $\mathrm{C}$ was given CREB $100 \mathrm{nM}$ + rapamycin $10 \mathrm{nM}$. Further, cells were grown in culture plate and incubated at the temperature of $37^{\circ} \mathrm{C}$ and $5 \% \quad \mathrm{CO}_{2}$. Measurement was conducted in each group on day 2,4 , and 6 .

\section{E. Cell Harvesting and Immunocytochemistry \\ Examination for the Activation of p70S6K1, CREB, $C / E B P \delta$}

Cell harvesting for immunocytochemistry was conducted as follows: plate was taken out from the incubator, placed in room temperature, and washed two times with PBS. Cells were fixed with $60 \%$ methanol for 10 minutes. After that, cells were washed two times with PBS, and the cells were ready for immunochemistry staining. Immunocytochemistry examination for the activation of p70S6K1, CREB, C/EBP $\delta$ followed the procedure in reference [7]. The determination of activation of p70S6K1, CREB, and $\mathrm{C} / \mathrm{EBP} \delta$ was conducted by counting the percentage of cells in slide which stained brown in the cytoplasm or nucleus in each field. From slides that have been stained, 5 fields were observed randomly with the magnification of 100x. Each field was divided into 4 quadrants, and number of cells stained brown was counted in each quadrant, and then the numbers were summed and counted as percentage against the total cells in each field. Final count is the average of cell percentage stained brown from 5 fields.

\section{F. Statistical Analysis}

Statistical analysis used in this study were normality test, Anova test, LSD test, and Pearson correlation test with $95 \%$ confidence level.

\section{RESULTS}

After $70-80 \%$ confluence was achieved, induction of differentiation was conducted to adipocytes, and then the treatment was given to each group. Transfection of siRNA CREB was conducted on confluent cells. Transfection of siRNA CREB was aimed to inactivate mRNA CREB. Efficiency of siRNA transfection in cells was determined by labelling it with fluoroscein isothiocyanate (FITC) and evaluated with confocal microscope after 24 hours. Result of evaluation of siRNA transfection efficiency is shown in Fig. 1. Average of percentage of p70S6K1 activation, CREB activation, and C/EBP $\delta$ activation were showed in Fig. 2 (a), (b) and (c) respectively.

Final process of adipocyte maturity is characterized by the 
change in cell morphology. Cell becomes spheric and accumulates lipid droplets. In this study, the change in cell morphology was evaluated on day 6 , near the end of adipogenesis process. Microscopic feature of Oil Red O staining is shown in Fig. 3. Mature cells showed more red staining, representing lipid droplets.

\section{A. Result of Statistical Analysis}

Based on the result of normality and homogeneity tests with $95 \%$ confidence level, it was concluded that all parameter data for all treatment groups and observation time were normally distributed and homogenous. One-way Anova test was conducted, and the result concluded that there was significant difference between at least 2 groups in each parameter and observation time. Afterwards, Pearson correlation test was conducted.

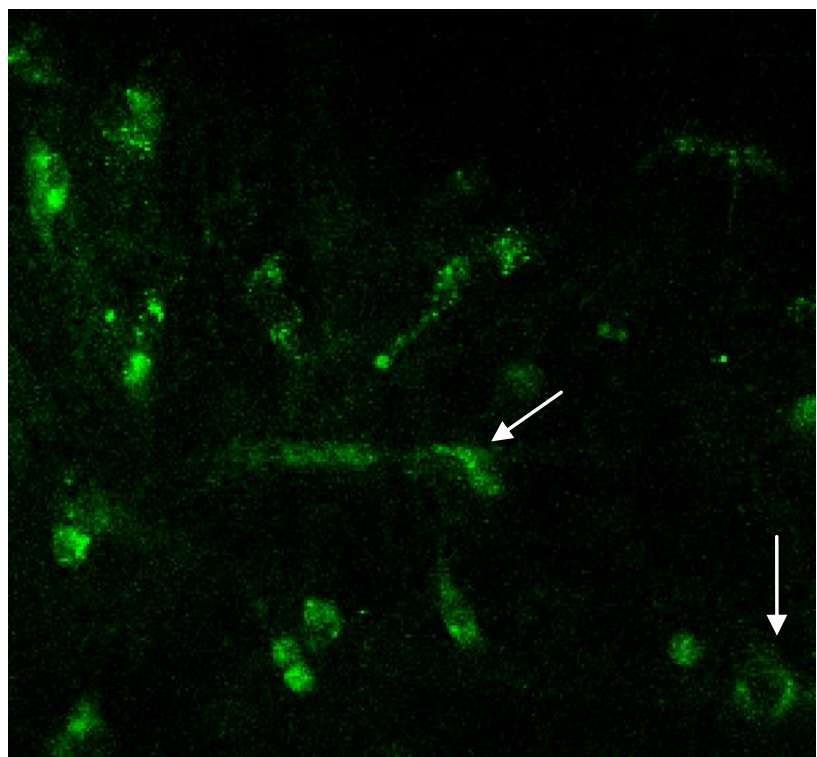

Fig. 1. Visualization of siRNA transfection efficiency in primary culture of preadipocytes after 24 hours, by using confocal microscope (magnification of 500x). Arrow showed siRNA which has been entered the cells, characterized by green fluoroscence in perinuclear site.
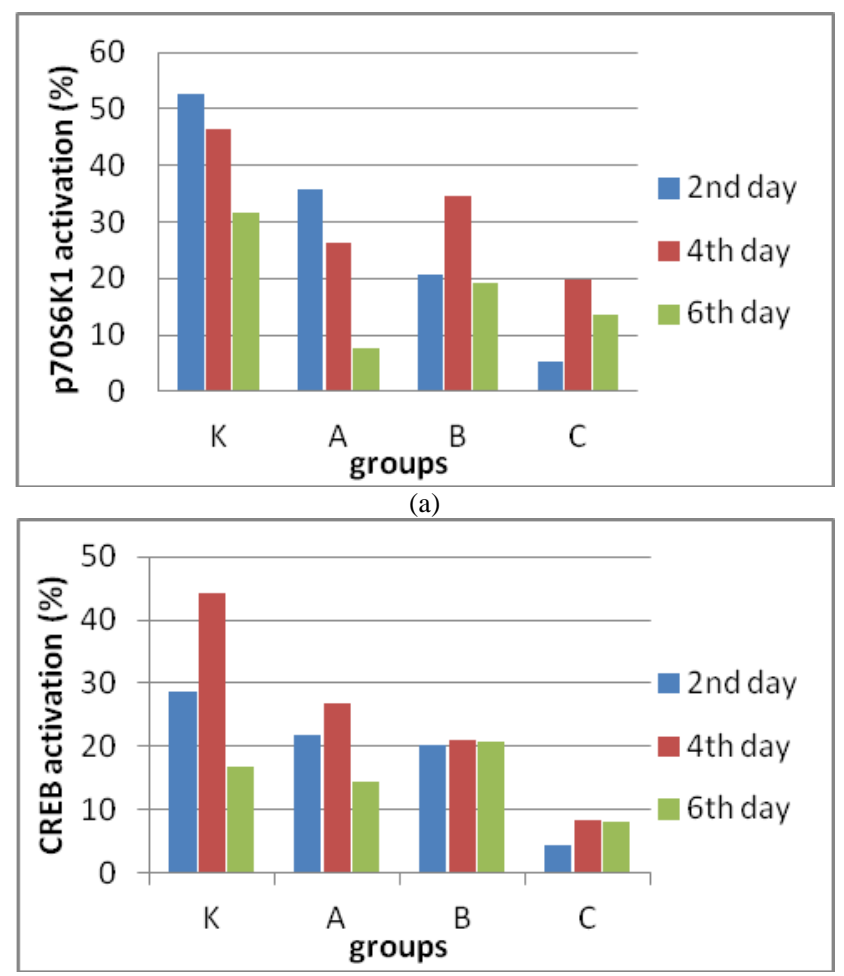

(b)

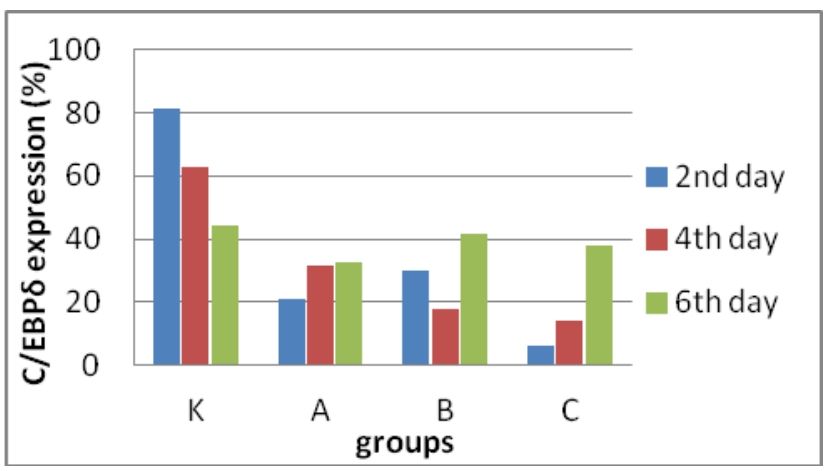

(c)

Fig. 2. Average of p70S6K1 activation (a); CREB activation (b); and $\mathrm{C} / \mathrm{EBP} \delta$ expression $(\mathrm{c})$ on preadipocyte after treatment on day 2,4 , and $6(\mathrm{~K}$ : induction of differentiation; A: induction of differentiation + rapamycin 10 $\mathrm{nM}$; B: induction of differentiation + siRNA CREB $100 \mathrm{nM}$; C: induction of differentiation + rapamycin $10 \mathrm{nM}+$ siRNA CREB $100 \mathrm{nM}$ )
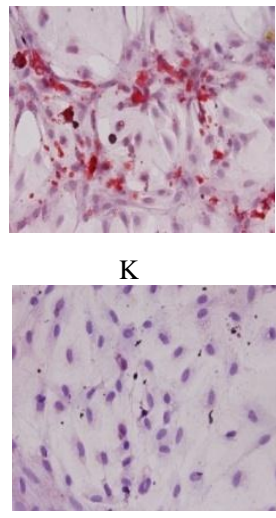

B

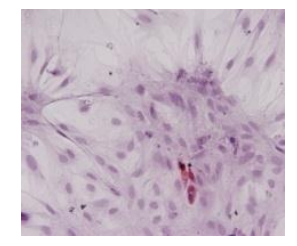

A

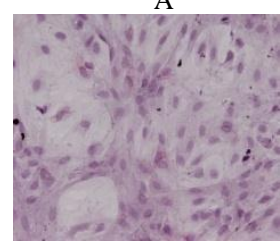

C
Fig. 3. Description of mature adipocytes on day 6 with Oil Red O staining showed more lipid droplets in control group (magnification of 300x). (K: induction of differentiation; A: induction of differentiation + rapamycin 10 $\mathrm{nM}$; B: induction of differentiation + siRNA CREB $100 \mathrm{nM}$; C: induction of differentiation + rapamycin $10 \mathrm{nM}+$ siRNA CREB $100 \mathrm{nM})$.

\section{DISCUSSION}

One pathway involved in adipogenesis is via mTORC1. mTOR is a serine/threonin protein kinase with the function of intracellular nutrient sensor to control protein synthesis, cell growth and metabolism [8]. mTORC1 protein is needed for adipocyte differentiation. mTORC1 activity is significantly increased in the liver, muscle, and adipose tissue of obese animal, both caused by genetic and diet, which showed the involvement of mTORC1 pathway in the peripheral site in the pathogenesis of obesity and metabolic disorder related with obesity [8].

\section{A. Acivation of $p 70$ S6K1}

p70S6 protein kinase is an insulin-sensitive serin/threonin kinase, located downstream to protein kinase $\mathrm{B}(\mathrm{PKB})$, although indirectly as PKB substrate. PKB may phosphorylate $\mathrm{mTORC} 1$, and then $\mathrm{mTORC} 1$ regulated p70S6K activity [6]. mTORC1 phosphorylated p70S6K1 on Thr 389, allowing phosphoinositide-dependent protein kinase 1 (PDK1) bound and phosphorylated S6K1 on Thr229, therefore, it fully activated S6K1. S6K1 stimulated protein synthesis and cell growth by phosphorylating various substrates, including translation inisiation component and/or elongation device [8].

In this study, measurement of phosphorylated p70S6K1 
activation was conducted with immunocytochemistry method. Groups who were given rapamycin (Group A and C) showed lower p-p70S6K1 activation compared with control. It established that rapamycin in the dose of $10 \mathrm{nM}$ might inhibit the action of mTORC1, so that it decreased the effectivity on p70S6K1. Rapamycin inhibited mTORC1 by forming a bond with $12 \mathrm{kDa}$ cytosolic protein, namely, FK-506-binding protein 12 (FKBP12), and inhibited its isomerization activity [9]. However, FKBP12 was not cytostatic target of rapamycin; instead, it became the determinant cofactor needed for the toxicity of rapamycin [10]. Rapamycin-FKBP12 complex inhibited mTORC1 pathway by directly binding mTORC1 at the rapamycin-sensitive site, namely, raptor. Specific mTOR1 phosphorylated S6 kinase ribosomal (S6K) and 4E-BP proteins at rapamycin-sensitive site. Deletion of S6KI, which is the physiological substrate of mTORC1, caused considerable metabolic defects at the peripheral site [8]. Rapamycin completely inhibited the activation of p70S6K1. Inhibition on the activation of p70S6K1 would directly affect other downstream factors. CREB is a transcription factor assumed affected directly by p70S6K1. Based on Pearson correlation test, it was concluded that there was a correlation between p70S6K1 and CREB ( $\mathrm{p}=0.000)$. This established that p70S6K1 phosphorylated CREB. Since p70S6K1 was downstream to mTORC1, it was concluded that mTORC1 was involved in the activation of CREB.

In this study, it was also found that activation of p70S6K1 would decrease, along with maturity process timing (Fig. 2a). Since p70S6K1 was upstream to the sequence of adipogenesis process through mTORC1 pathway, the activation was the highest on day 2 , and then it was decreased on day 4 and 6 . However, in group B and C, activation of p70S6K1 on day 2 was lower than that on day 4, and then it was decreased more on day 6 . It was suspected that on day 2 , cell adaptation to medium change was still occurred, resulted in the slow activation of p70S6K1.

\section{B. Activation of CREB}

CREB protein is one of the transcription factors. It binds on certain DNA sequence referred to as cAMP response elements (CRE), and increases or decreases the transcription of downstream genes [11]. However, little is known about the phosphorylation of CREB by mTORC1 through p70S6K1.

In this study, to prove that CREB has a role in adipogenesis and associated with p70S6K1, RNAi CREB was used as the inhibitor for CREB action. RNAi CREB is a process where intracellular pathway activation modulated by small-interfering RNA (siRNA) consisted of 21-23 nucleotides induces the degradation of specific mRNA target [12]. In Fig. 1, location of siRNA in perinuclear site showed that siRNA has entered the cells. Location in perinuclear site was correlated with the efficacy of RNAi [12].

In this study, CREB activation in group who was given rapamycin was lower than that of control, while group who was given the combination of RNAi CREB and rapamycin showed the lowest activation (Fig. 2(b)). This established that CREB activation was affected by mTORC1 through the phosphorylation of p70S6K1. Phosphorylated p70S6K1 protein would phosphorylate CREB on $\mathrm{Ser}^{133}$. Therefore, aside from PKA, CaMK, and growth factor, mTORC1 was also the upstream effector of CREB. This has been established statistically by Pearson correlation test that there was a significant correlation between p70S6K1 and CREB, with correlation coefficient of $0.987 \quad(p=0.000)$. Phosphorylated CREB will induce the downstream genes, $\mathrm{C} / \mathrm{EBP} \delta$.

Study by Zhang et al. proved the role of CREB in transcriptional regulation of $\mathrm{C} / \mathrm{EBP} \beta$ during adipogenesis. The phosphorylation of CREB and ATF1 increased the binding to regulator element on $\mathrm{C} / \mathrm{EBP} \beta$ gene promotor, primary phosphorylation effect of CREB and ATF1 showed the transactivation of $\mathrm{C} / \mathrm{EBP} \beta$ gene. Activation of gene expression and CREB and ATF1 phosphorylation was only occurred after induction of adipogenesis [13]. Other study by Vankoningsloo proved that the activation of CREB induced by mithochondrial dysfunction has triggered the accumulation of triglyceride in preadipocyte 3T3-L1. It established the role of CREB in adipogenesis process [14]. However, those studies did not associate the activation of CREB and p70S6K1

In Fig. 2(b), on day 6, the activation of CREB in group B and $\mathrm{C}$ was not considerably different compared with that on the day 2 and 4 . Based on the comparation test between observations and between treatments, result showed that there was no significant difference between day 6 and day 2 . It might be occurred because the reversible administration of RNAi. After day 4, degradation effect of mRNA CREB by RNAi molecule was started to disappear and gradually returned to the previous condition, so that on day 6 , there was no decrease of CREB as shown in the other groups.

\section{Expression of $C / E B P \delta$}

One of the first steps of adipogenesis is the increase in expression and accumulation of CCAAT/enhancer-binding proteins $\mathrm{C} / \mathrm{EBP} \beta$ and $\mathrm{C} / \mathrm{EBP} \delta$ transcription factor, which occurs in 1-4 hours of induction of adipogensis, but initially it is still inactive. $\mathrm{C} / \mathrm{EBP} \beta$ and $\mathrm{C} / \mathrm{EBP} \delta$ increased adipogenesis, mainly on the part which induced $\mathrm{C} / \mathrm{EBP} \alpha$ and PPAR $\gamma$ [15], [16]. However, the role of $\mathrm{C} / \mathrm{EBP} \delta$ in adipogenesis process is less often discussed compared with $\mathrm{C} / \mathrm{EBP} \beta$.

In this study, the expression of $\mathrm{C} / \mathrm{EBP} \delta$ in control group on day 2 was higher than day 4 (Fig. 2(c)). It brought the assumption that normally the activation of $\mathrm{C} / \mathrm{EBP} \delta$ was earlier. However, in treatment groups, expression of $\mathrm{C} / \mathrm{EBP} \delta$ was increased on day 4 and 6 , although it was insignificantly different. In group B and $\mathrm{C}$ who were given RNAi CREB, the increase phenomenon in $\mathrm{C} / \mathrm{EBP} \delta$ expression on day 6 was shown. Expression of $\mathrm{C} / \mathrm{EBP} \delta$ on day 6 was not significantly different with control group. It is suspected that results from the administration of RNAi CREB in group B and C were reversible. Similar with the expression of CREB, after day 4, degradation effect of mRNA CREB by RNAi molecule started to disappear and gradually returned to previous condition, so that on day 6 , there was a decrease in CREB, similar with that in the other groups. It was suggested that $\mathrm{CREB}$ had role in inducing $\mathrm{C} / \mathrm{EBP} \delta$. Correlation test between $\mathrm{CREB}$ and $\mathrm{C} / \mathrm{EBP} \delta$ concluded that there was a significant association, with correlation coefficient of $0.975(p=0.000)$.

Study by Kim \& Chen using rapamycin on preadipocyte 3T3-L1 concluded that the administration of rapamycin for 8 days resulted in the decrease in lipid droplets and smaller 
adipocytes, suggested that rapamycin affected the maintenance of adipogenic characteristics in mature adipocytes. Their study also showed that C/EBP $\beta$ and $\mathrm{C} / \mathrm{EBP} \delta$ levels would highly increased one day after induction, and after day 4 it was gradually decreased until day 8 in control group [17]. It is similar with the result of this study. However, in the study by Kim \& Chen, it was reported that activation of $\mathrm{C} / \mathrm{EBP} \alpha$ by $\mathrm{C} / \mathrm{EBP} \delta$ and $\mathrm{C} / \mathrm{EBP} \beta$ did not depend on the function of mTORC1. Meanwhile, in this study, in group who was given rapamycin, expression of $\mathrm{C} / \mathrm{EBP} \delta$ was lower than control group. It was suggested that mTORC1 affected the expression of C/EBP $\delta$.

\section{CONCLUSION}

Based on the result of this study, it was concluded that there was an assocation between the activation of p70S6K1 by mTORC1 and the activation of CREB and between activation CREB and expression of $\mathrm{C} / \mathrm{EBP} \delta$. The inhibition of mTORC1 by rapamycin might prevent the adipogenesis process through CREB pathway, which meant that CREB had a role in adipogenesis process through the activation of p70S6K1 by mTORC1.

\section{ACKNOWLEDGMENT}

This study is funded by Ministry of Health, Republic of Indonesia, through Risbin Iptekdok Program 2012 from Balitbangkes.

\section{REFERENCES}

[1] W. M. S. Plantenga, A. Smeets, and M. P. G. Lejeune, "Sensory and gastrointestinal satiety effects of capsaicin on food intake," Int $J$ Obes, vol. 29, pp. 682-688, 2005.

[2] A. J. Walley, I. F. Alexandra, and F. Philippe, "Genetics of obesity and the prediction of risk for health," Hum Mol Genet (Review issue no. 2), vol. 15, pp. R124-R130, 2006.

[3] Obesity and Overweight, World Health Organization, 2006, Download on July, $23^{\text {rd }} 2009$.

[4] M. M. Musri, R. Gomis, and M. Parrizas, "Chromatin and chromatin-modifying proteins in adipogenesis," Biochem Cell Biol, vol 85 , pp. 397-410, 2007.

[5] O. Bacquer, E. Petroulakis, S. Pagllalunga, F. Poulin, D. Richard, K Clanflone, and N. Sonenberg, "Elevated sensitivity to diet-induced obesity and insulin resistance in mice lacking 4E-BP1 and 4E-BP2," $J$ Clin Invest, vol. 117, pp. 387-395, 2007.

[6] D. El-Chaar, A. Gagnon, and A. Sorisky, "Inhibition of insulin signaling and adipogenesis by rapamycin: Effect on phosphorylation of p70 S6 kinase vs eIF4E-BP1," Int J Obes, vol. 28, pp. 191-198, 2004.

[7] M. R. Indra, T. E. Hernowati, Satuman, and E. Widodo, Kultur Adiposit dan Pemeriksaan Adipositokin, Malang: Laboratorium Ilmu Faal Fakultas Kedokteran Universitas Brawijaya, 2010.

[8] L. Rui, "A link between protein translation and body weight," J Clin Invest, vol. 117, pp. 310-313, 2007.

[9] L. Liu, F. Li, J. A. Cardelli, K. A. Martin, J. Blenis, and S. Huang, "Rapamycin inhibits cell motility by suppression of mTOR-mediated S6K1 and 4E-BP1 pathways," Oncogene, vol. 25, pp. 7029-7040, 2006.

[10] C. De Virgilio and R. Loewith, "Cell growth control: Little eukaryotes make big contributions," Oncogene, vol. 25, pp. 6392-6415, 2006.

[11] P. Haus-Seuffert and M. Meisterernst, "Mechanisms of transcriptional activation of cAMP-responsive element-binding protein CREB," Mol Cell Biochem, vol. 212, pp. 5-9, 2000.

[12] Y. Chiu, A. Ali, C. Chu, H. Cao, and T. M. Rana, "Visualizing a Correlation between siRNA Localization, Cellular Uptake, and RNAi in Living Cells," Chem Biol, vol. 11, pp. 1165-1175, 2004.

[13] J. W. Zhang, D. J. Klemm, C. Vinson, and D. Lane, "Role of CREB in Transcriptionl Regulation of CCAAT/Enhancer-binding Protein $\beta$

Gene during Adipogenesis," J Biol Chem., vol. 279, pp. 4471-4478, 2004.

[14] S. Vankoningsloo, A. D. Pauw, A. Houbion, S. Tejerina, and C. Demazy, "CREB activation induced by mitochondrial dysfunction triggers triglyceride accumulation in 3T3-L1 preadipocytes," Journal of Cell Science, vol. 119, pp. 1266-1282, 2006.

[15] E. D. Rosen and O. A. MacDouglad, "Adipocyte differentiation from the inside out," Nat Rev Mol Cell Biol, vol. 7, pp. 885-896, 2006.

[16] E. D. Rosen, "The molecular control of adipogenesis, with special reference to lymphatic pathology," Ann N Y Acad Sci, vol. 979, pp. $143-58,2002$.

[17] J. E. Kim and J. Chen, "Regulation of peroxisome proliferation-activated receptor- gamma activity by mammalian target of rapamycin and amino acids in adipogenesis," Diabetes, vol. 53, pp. 2748-2756, 2004.

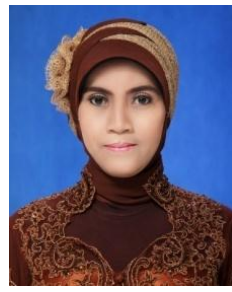

Indonesia
Triawanti was born in Surabaya, Indonesia, in September 1971. She was graduated as a physician in 1998 from Lambung Mangkurat University, Banjarmasin, Indonesia. She was graduated master degree 2004 from Airlangga University, Surabaya, Indonesia, PhD 2012 from Brawijaya University, Mal ang, Indonesia. She currently work in Medical Biochemistry Department, Faculty of Medicine, LaLambung Mangkurat University, Banjarmasin,

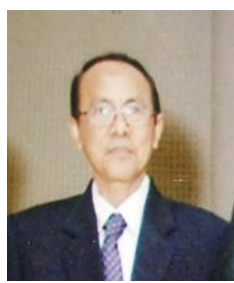

M. Rasjad Indra was born in Gresik, East Java, Indonesia in Mei 1950. He was graduated as a general doctor in 1977 from Airlangga University, Surabaya, Indonesia. He received master degree in 1986 and Phd in 1997 from Airlanngga University, Surabaya, Indonesia.. His research is mainly focused on biochmecial and physiological medicine.

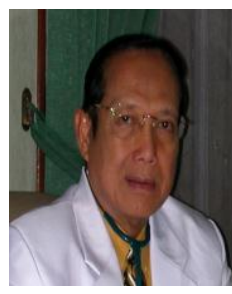

Askandar Tjokroprawiro was born in Kediri, East Java, Indonesia in July 1939. He was graduated as general doctor in 1964, as internist in 1968, Phd in 1978 from Airlannga Univesity, Surabaya, Indonesia. He has published a hundreds scientific jurnal or confernce papers. His research is mainly focused on endocrinology, human metabolism and diabetes mellitus.

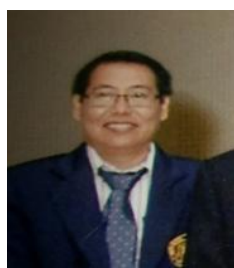

Hidayat Sujuti was born in Gresik, East Java Indonesia, in January 1967 . He currently work as the head of Biochemistry Department, Medical Faculty, Brawijaya University, Malang, Indonesia.

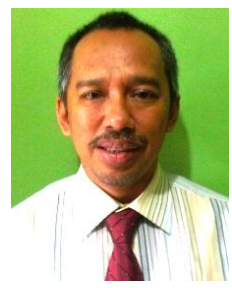

Eko Suhartono was born in Surabaya, Indonesia, in September 1968. He received his bachelor degree from Sepuluh Nopember of Institute Technology in 1991 and M. Sc degree in 1998 from Gadjah Mada University, Yogyakarta, Indonesia. He currently study environmental science and technology graduate program in Brawijaya University, Malang, Indonesia. His research is mainly focused on free radical and natural product antioxidant, ecotoxicology. He has published more than 40 scientific journal or conference papers. 